\title{
REVIEW OF PLASTIC DRAINAGE IN THE NETHERLANDS ${ }^{1}$ )
}

\author{
A. W. DE JAGER
}

Research Division Nederlandsche Heidemaatschappij, Arnhem, Netherlands

\begin{abstract}
SUMmary
After a description of drainage circumstances and the possibilities of mole drainage, follows a review of the experiences with plastic drainage in The Netherlands.

Polyethylene tubes are pulled behind a mole plow from the ditch side into the subsoil, plastic strips are laid with a specially designed mole plow and plastic pipes are installed with a conventional machine for tile drainage.

Besides field experiments there are made sand tank investigations about deformation, sand infiltration and discharge of plastic strips and in the case of plastic pipes a comparison is made about drainage results between different perforated plastic pipes and normal tile drains.
\end{abstract}

\section{InTRODUCTION}

During the last years the use of plastic materials for subdrainage has been investigated in various countries. Works on this subject of JANERT (1) in Eastern Germany and Busch (2) in the USA are well-known.

To reduce the cost of subsurface drainage and to mechanize the execution of the drainage works in The Netherlands, polyethylene tube and rigid p.v.c. strips and pipes are used. In this report is a review of the investigations and installation methods of plastic drains.

In order to compare these methods with those in other countries it is first of all necessary to have a good notion of the drainage-circumstances in The Netherlands.

\section{Drainage-Circumstances}

\section{a Drainage systems}

There are two main groups in which we can divide the drainage systems, groundwater-drainage and heavy land drainage. In the case of groundwaterdrainage the tiles have the function of lowering the water table. In a homogeneous soil with an impervious stratum at great depth the greater part of the flow of water is below drainlevel. In heavy soils with a slight permeability the backfill in the drain ditches will often have a relatively great conductivity, so that the rainfall is mainly discharged through the mould directly to the ditches, whereby we get a flow pattern quite different from the above mentioned.

Heavy soils accompanied by sloping land usually have a deep groundwater level, and especially in these soils mole-drainage is applied with success. In flat areas and slight permeable soils tile-drainage removes rainfall partially as groundwater and partially as surface water through the drain ditches.

The drainage area in The Netherlands embraces almost only slightly sloping regions or no slopes at all and at any rate the subsurface-drains lie in groundwater for the greater part of the year. Moreover, the subsoil mostly consists of silty loam or fine sand.

1) Received for publication August 23, 1960. 
Deterioration of mole-drains in these circumstances may be expected, as the most important factors to get a stable mole-channel are heavy clay soil and a deep groundwater table.

Improved mole-drainage by adding or inserting material gives the best possibilities to constitute subsurface drainage at low cost. In the Dutch soils, however, the added materials must give a sufficient stability starting from the fact that the mole-channel is not stable.

On the other hand the operation of excavating and refilling the ditch with permeable material has hydraulic advantages over the small blade-slit of the mole drain, especially in heavy soils.

\section{$\mathrm{b}$ The cost of tile-drainage}

In Holland the initial cost of a mechanized installation for clay tile drainage, without covering the tiles with peat, are about $f 0,90$ to $f 1$,- per metre, consisting of $f 0,30$ to $f 0,40$ for the purchase of clay tiles and $f 0,50$ to $f 0,60$ for labour and equipment. The average output of a drainage-machine is about 200 metres an hour, in which is calculated the time lost on account of repairs, transport, unfavourable weather etc.

In The Netherlands clay tiles are of a very good quality and suitable for being automatically laid by the machine.

For these reasons it is not easy to invent a new drainage system which is less expensive and which has a drainage performance as good as the conventional tile-drainage. However, the machine laying tile drainage requires much hand-labour for transport, distribution and laying tiles and even more is needed when peat is used for covering the tiles.

\section{Plastic tubes}

In 1956 first investigations were made with pulling into the soil a polyethylene tube behind the mole-plow. A tube with a length of $200 \mathrm{~m}$ was pulled from the ditch side into the subsoil at a depth of $0.90 \mathrm{~m}$. The inner and outer diameter were respectively 40 and $45 \mathrm{~mm}$. The tube was perforated with saw-slits perpendicular to the axis spaced at intervals of $0,5 \mathrm{~cm}$, so that the water could enter.

Width of the slits was $0,075 \mathrm{~cm}$, length inside $0,5 \mathrm{~cm}$ and outside $1,5 \mathrm{~cm}$. The trial was done in a marine deposit consisting of silty loam.

Although the water level was above the drains during a long time the discharge by the plastic tubes was very low in comparison with the tile drains in the same conditions. About the failure of these drains two suppositions were made.

First, compression of the soil by pulling the mole drains, which causes a less pervious layer around the channel. It was calculated by Wesseling (3) that a $50 \%$ decrease of the hydraulic conductivity with relation to the surrounding soil causes a decrease in drain discharge of $30 \%$. In the second place it was supposed that the slits were clogged by silt when pulling the tube into the mole-channel.

The plastic tube of polyethylene is expensive compared with the total cost of conventional tile-drainage. This was the main reason why further fieldresearches into this type of plasticdrainage has not been made. 


\section{Plastic STRIP}

\section{a Field experiments}

To reduce the cost of subsurface drainage the most favourable conditions are acquired by using plastic strip in combination with mole-drainage. Besides the simple method of drainage, plastic strip has much advantage when it is transported, due to the slight bulk and weight of this material. Therefore it is easily understood why in several countries this principle is developed at approximately the same time. Different methods with respect to this subject are described by Janert (1), Busch (2) and Juusela (4).

The first plastic lined mole-channels were installed in the Netherlands in 1957. This operation was performed in a marine deposit consisting of silty
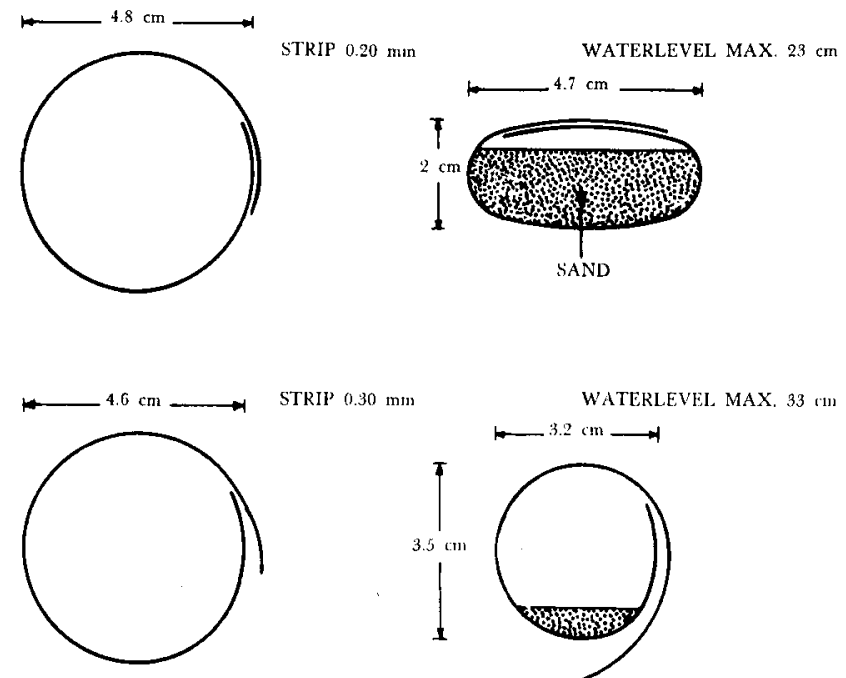

STRIP $0.30 \mathrm{~mm}$
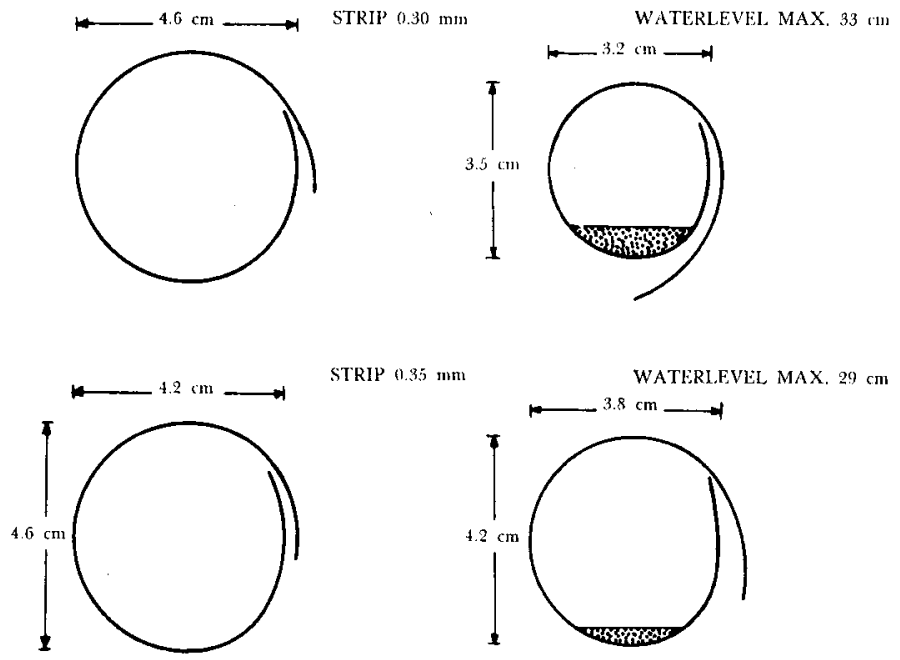

STRIP $0.35 \mathrm{~mm}$
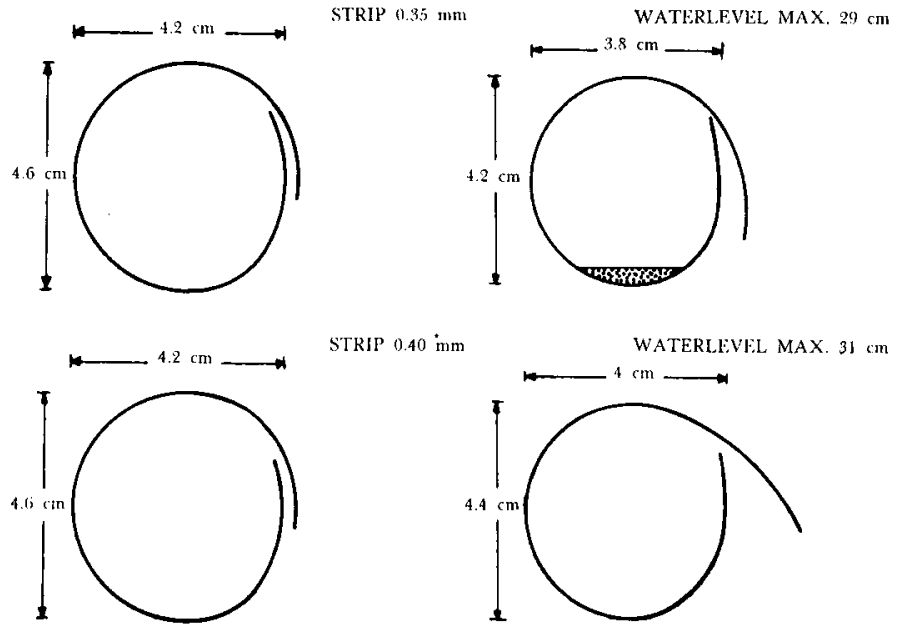

STRIP $0.40 \mathrm{~mm}$

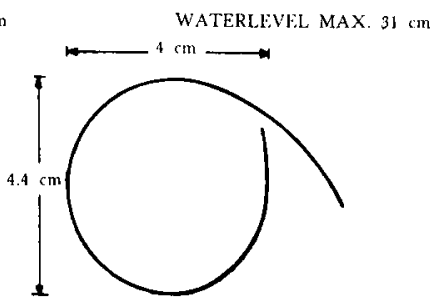

Fig. 1 Cross sections of plastic strips, $0,20,0,30,0,35$ and $0,40 \mathrm{~mm}$ Thick. ON The LEFT SIDE: IMMEDIATELY AFTER INSTALLATION. ON THE RIGIT SIDE : DEFORMATION AND SAND INFILTRATION AFTER THE WATER TABLE HAD RAISED TO THE STATED LEVEL. 
loam soil at a time when the groundwatertable was low. The strip, $16 \mathrm{~cm}$ wide and $0,20 \mathrm{~mm}$ thick, was put into the soil by a specially designed moleplough at a depth of about $0,80 \mathrm{~m}$. Immediately behind the mole blade there was a second hollow blade, in which the strip was led down. At the bottom the strip was bent rectangular and afterwards in the mole channel transformed to a continuous tube by a specially constructed funnel. The shape of such a tube is shown in figure 1 ; here the overlapping edges of about $1 \mathrm{~cm}$ were at the sidewalls. The diameter of the tube was about $4,8 \mathrm{~cm}$. Water should enter the tube by a longitudinal gap at the overlapping.

Two months later, after the watertable had raised above drain-level, it was found, by digging up the drains, that the plastic strips were completely pressed together. In consequence of this experience we made a systematic research about thickness and perforations of plastic strips with respect to deformation and discharge.

A sand tank was used for making rapid comparisons between various types of strips.

\section{b Sand tank research}

The sand tank for drainage investigations, which is shown in figure 2, measures $1.20 \mathrm{~m}$ high, $2 \mathrm{~m}$ between side walls and $1 \mathrm{~m}$ wide. The length of the drain which is to be tested is also $1 \mathrm{~m}$. Over the tank are two sprinkler

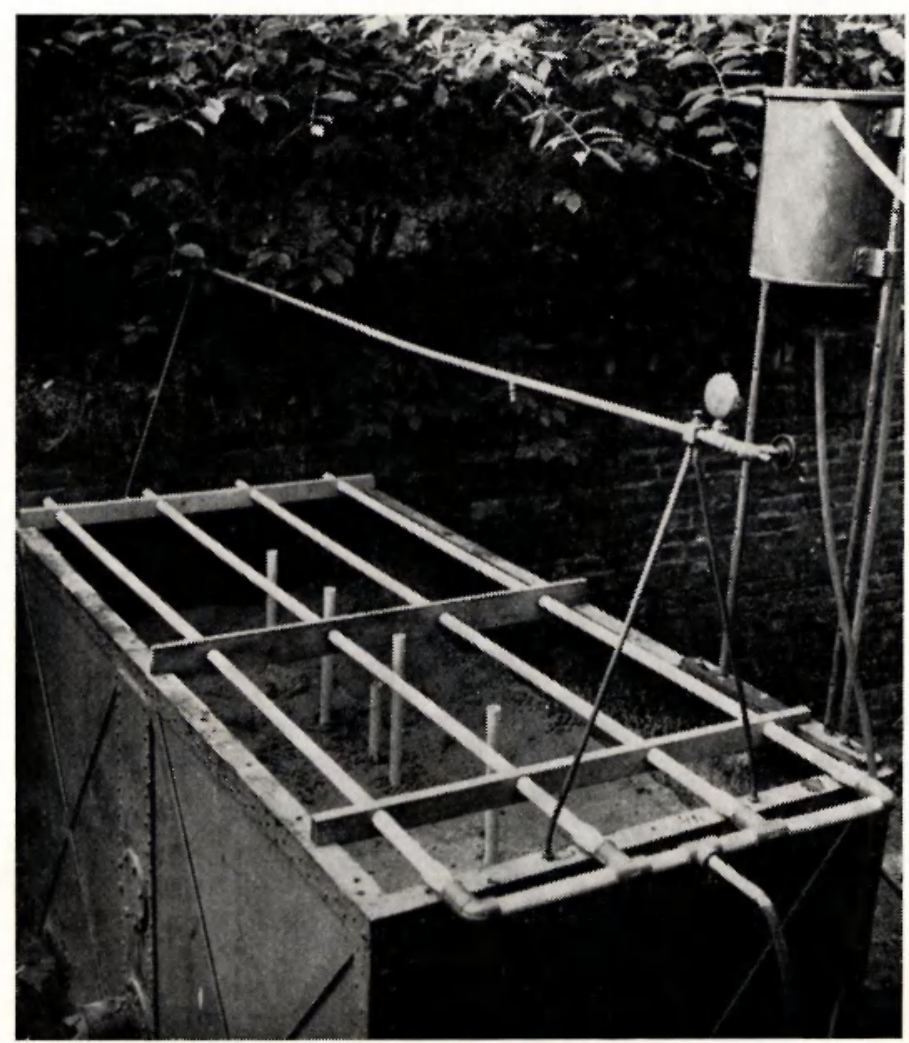

Fig. 2 SAND taNk With SPRINKLER installations aNI piezometehs. 


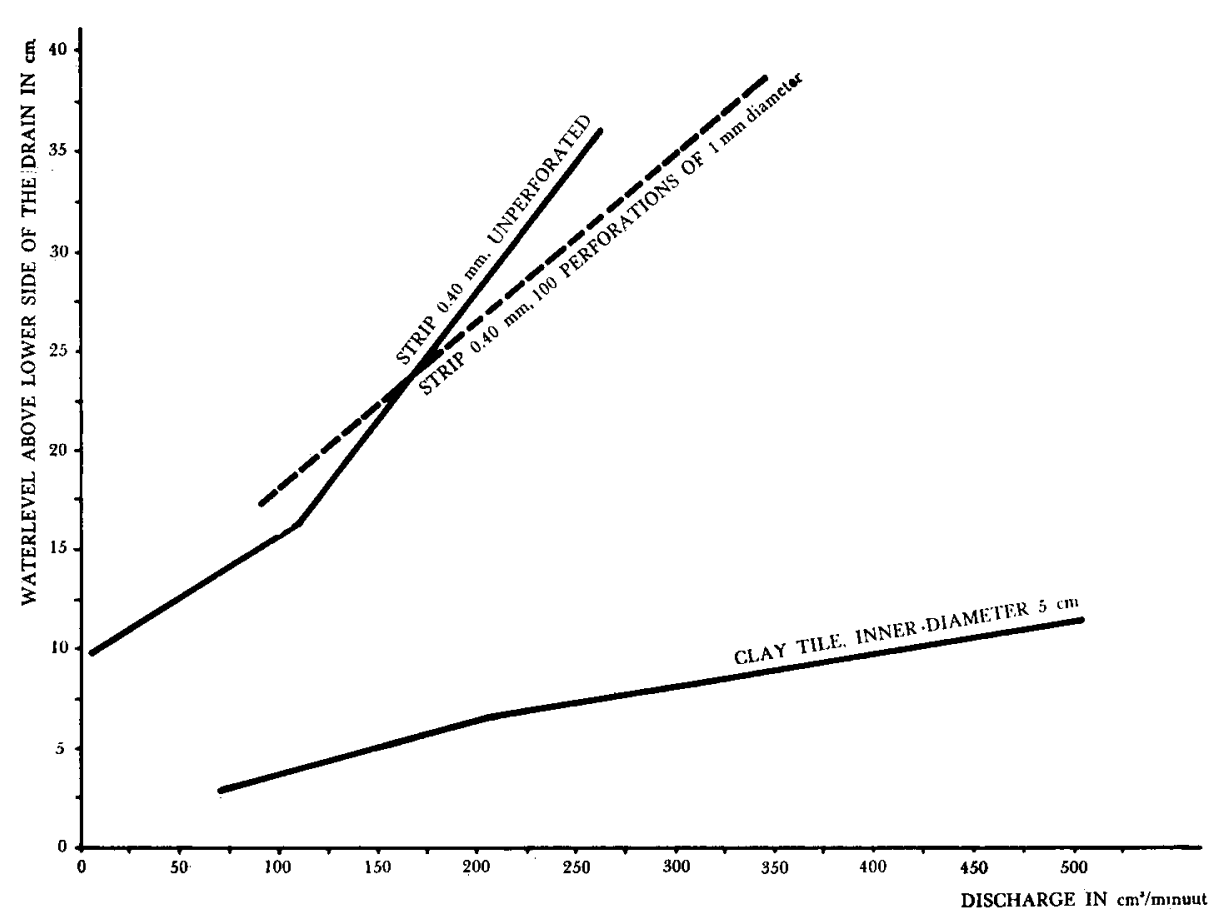

Fig. 3 Hydraulic head and drain discharge of plastic strips and tile drains.

installations, giving an equally distributed rainfall of respectively 46 and $6 \mathrm{~mm}$ an hour.

The tank was filled to a height of $0.90 \mathrm{~m}$ with sand, which had an uniform size distribution and a hydraulic conductivity of $8 \mathrm{~m} /$ day.

Drains were put in $0.40 \mathrm{~m}$ above the bottom of the tank, so $0.50 \mathrm{~m}$ below the sand surface. In a row perpendicular to the drain, piezometers were placed at distances of $50 \mathrm{~cm}$ (on each side), $20 \mathrm{~cm}$ and $10 \mathrm{~cm}$. In front of the tank drain discharge could be measured with a calibrated vessel; at the back the drain was closed by a glass plug, which allowed observation of the inside during the test. In general, observations were made about drain discharge with accessory hydraulic heads, sand infiltration and also deformation at the plastic strip. To imitate field conditions as far as possible the plastic strip was attached to a mole-spindle which was pulled through the sand-filled tank by means of a steel wire and winch.

Strips $16 \mathrm{~cm}$ wide and $0,20,0,30,0,35$ and $0,40 \mathrm{~mm}$ thick were examined.

After the drains had been installed, the watertable was raised by sprinkling. Dependent on the thickness, the plastic strip was rolled up when the waterlevel raised above the tube. Sand infiltration was found in the $0,20 \mathrm{~mm}$ strip and in lessening degree also in the 0,30 and $0,35 \mathrm{~mm}$ strips.

Figure 1 shows cross sections of the plastic tubes before and after the tests, as well as the amounts of sand deposit. The strips gradually rolled up at increasing waterlevel. In figure 1 we give the highest observed waterlevels in the piezometer, $10 \mathrm{~cm}$ from the drain. By lowering the watertable the tubes did not come back in their original position. Several tests were made with the same type of strip with approximately similar results. 
In order to lower the hydraulic head at a fixed discharge above the drain, the strips were perforated with circular gaps of $1 \mathrm{~mm}$ diameter. The number of perforations varied from 50 to 200 per metre. Perforation of the strip gave a better drainage performance, as is shown in figure 3 . In figure 3 we give the relation between the waterlevel above the lower side of the drain at $10 \mathrm{~cm}$ distance and the drain discharge. To compare it with conventional drainage the same relation is determined for clay tiles, with a $5 \mathrm{~cm}$ inner diameter. Obviously, with respect to a tile-drain the flow of water into a plastic lined drain has to overcome a much larger resistance.

With respect to the above mentioned results it may be stated that under field conditions plastic strips 0,20 and $0,30 \mathrm{~mm}$ thick are not suitable for lining mole channels.

The $0,40 \mathrm{~mm}$ strip is rather good, but it is not quite impossible that after some time this strip will collapse somewhere.

Therefore it is recommendable to fasten the edges of the strip and, to lower the hydraulic head, perforate the strip.

Investigations in this way have not yet been made until now.

\section{Plastic PIPES}

\section{a Why plastic pipes?}

In chapter 2 it has been pointed out that for a good drainage system it is desirable to dig a trench in order to have permeable soil around the drain. The same result may be reached by using a type of mole-plow which lifts up the soil.

In that case a heavy mole-plow requiring high tractive power should be available. In view of the cost of the plastic strip for lining the mole channel and because of the smaller drain distance, a much higher output of the drainage equipment is necessary for lowering the total drainage cost per acre. In flat areas where an accuracy of $1-2 \mathrm{~cm}$ in drain slope is demanded, a high quickness is only possible by an automatical adjustment of depth. At the present, however, such a system for drainage work is not available.

For these reasons a draininstallation with rigid plastic pipes is developed at the moment. Pipes $6 \mathrm{~m}$ long are carried on the drainmachine, which is the same as used for laying clay tiles. At one side the pipes are widened, by which it is possible to fasten the separated pipes on the machine in an easy way. The pipes are bended and led into the machine so that it reaches the bottom of the ditch inside the plates which are at the back of the ditching apparatus (figure 4). The machine is operated by only two men and compared with conventional installation methods about five men can be saved. In spite of the higher material cost, $f 0,50 / \mathrm{m}$ for plastic pipes to $f 0,30 / \mathrm{m}$ for clay tiles, the total installation cost are about the same.

The most important advantage of this type of drainage is its high degree of mechanization leading to an increase in labour-productivity. Cost of transport are negligible in comparison with ordinary tiles. A $4 \mathrm{~cm}$ diameter pipe with a wall-thickness of $0,8 \mathrm{~mm}$ weighs $140 \mathrm{gr}$ per metre.

At the present the machine operates at normal speeds of about 300-400 metres an hour. It is reasonable to suppose that with plastic pipes it is pos- 


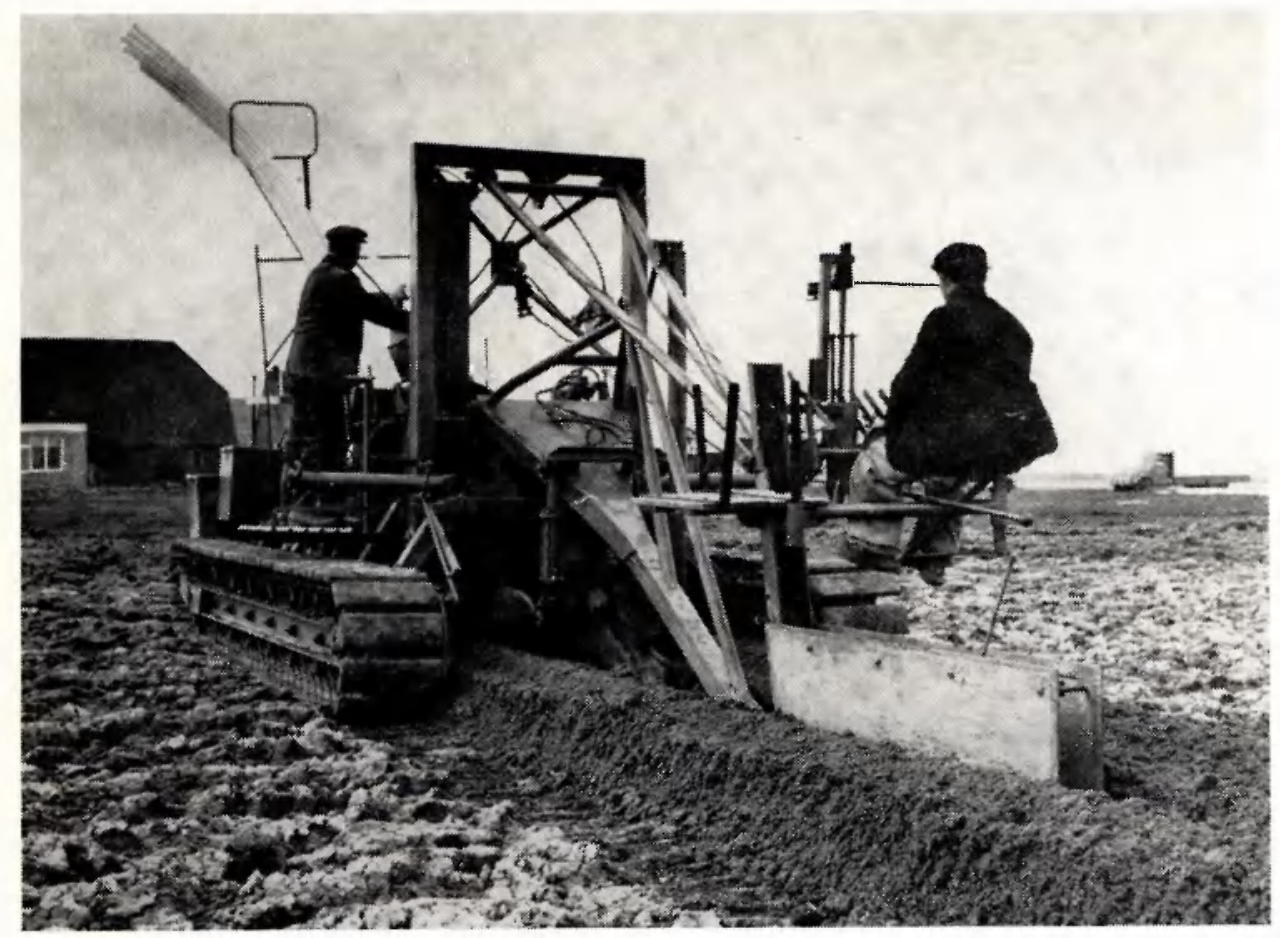

Fig. 4 Machine laying plastic pipes.

sible to work at higher speeds. For the speed of the machine is not dependent on the supply of material and adjustment of the tiles after laying. Moreover it may be expected that, when plastic drainage is in general use, special machines for laying plastic pipes will be constructed, whereby it is possible to reduce the width of the trench from $25 \mathrm{~cm}$ to about $10 \mathrm{~cm}$. For general use it is important to bear in mind that with respect to plastic lined mole channels drainage with rigid plastic pipes gives more security against collapsing and clogging of the drain.

\section{b Investigations on perforation of plastic pipes}

The basic problem to investigate was, how to perforate the plastic pipes, so that they have a drainage performance as good as a tile drain. Therefore the pipes were examined in the same sand tank model as described at the investigations of the plastic strip. Plastic pipes with different diameters and perforations were put into the tank and laid in a trench.

The examined drain-length was $1 \mathrm{~m}$. The water supply was regulated by the sprinkling installation over the tank, giving an equally distributed rainfall. The different plastic pipes were compared with each other and with clay tiles by measuring groundwatertable and drain discharge at the same time. During the observation steady conditions were approximately reached.

A good insight of the efficiency of a particular drain can also be formed by observing the control, which the drain exercises on the performance and by comparing this with conventional tiles. The tested plastic pipes differed in 
diameter and length and number of longitudinal slits; in cases of tile tests there were three joints inside the sand tank. The tiles had a length of $30.5 \mathrm{~cm}$ and an inner- and outer diameter of respectively 5 and $7.5 \mathrm{~cm}$.

The total area of perforations per metre was limited for practical reasons. To obviate fracturing the pipe when it is bent in the drainmachine the slits must be placed longitudinal on the walls. Long slits are closed much easier by soil pressure than short ones; for technical reasons the shortest possible slits to saw were $2-2.5 \mathrm{~cm}$ long. In order to prevent the entrance of soilparticles in the drain the width of the slit may not be too large; for the moment it was fixed on $0.6 \mathrm{~mm}$, because with slits larger than $0.7 \mathrm{~mm}$ silting up was found at the tank experiments. To preserve the strength of the pipe the area of perforations was restricted to $9 \mathrm{~cm}^{2} / \mathrm{m}$, so 60 slits per metre and the perforations equally distributed on the circumference.

For laterals $5 \mathrm{~cm}$ inner diameter clay tiles are in common use; this diameter is amply sufficient by a mean discharge of $20 \mathrm{l} / \mathrm{min}$ and $0.10 \%$ grade. Due to the lower hydraulic roughness of the plastic pipe it is possible to use $4 \mathrm{~cm}$ diameter plastic drains for almost any length of laterals which are found in the field. In The Netherlands most laterals have a length of 100$200 \mathrm{~m}$, a mutual distance of $8-20 \mathrm{~m}$ calculated with a run-off modulus of $7 \mathrm{~mm} /$ day.

For calculating the drainage performance under field conditions the particular drains were characterized by determining the loss of hydraulic head caused by the resistance of the flow at the entry point (entry resistance). The flow of water in the vicinity of the drain can be divided in radial flow and entry flow. The beginning of the radial flow is given by Hooghoud (5) at a distance $0.7 \mathrm{D}$ ( $\mathrm{D}$ is depth impermeable layer beneath drain level), it is also about the boundary between horizontal and radial flow. In the case of this sand model the total hydraulic head for radial- and entry resistance was represented by the waterlevel at about $30 \mathrm{~cm}$ distance from the drain $(\mathbf{D}=$ $0.40 \mathrm{~m}$ ). This waterlevel minus the calculated hydraulic head for radial flow gives the head the entry resistance $\left(\triangle \mathrm{h}_{s}\right)$ to overcome.

Hydraulic heads for radial $\left(\Delta h_{s}\right)$ and entry flow $\left(\Delta h_{x}\right)$ are determined by the following equations of ERNsT (6) (7):

$$
\triangle \mathrm{h}_{\mathrm{r}}=\frac{\mathrm{Q}}{\pi \mathrm{k}} \ln \mathrm{D} / \mathrm{u} \text { and } \Delta \mathrm{h}_{\mathrm{x}}=\alpha_{\mathrm{k}}^{\mathrm{Q}}
$$

where: $\mathrm{k}=$ permeability ( $\mathrm{m} /$ day)

$\mathrm{Q}=$ drain discharge per $\mathrm{m}$ drain $\left(\mathrm{m}^{2} /\right.$ day $)$

$\mathrm{D}=$ height of installation above underlying impermeable layer $(\mathrm{m})$

$\mathrm{u}=$ wet surface $(\mathrm{m})$

$\alpha=$ coefficient.

Coefficient $\alpha$, calculated for any separate drain, appeared to be a constant, independent of the quantity of discharge. 


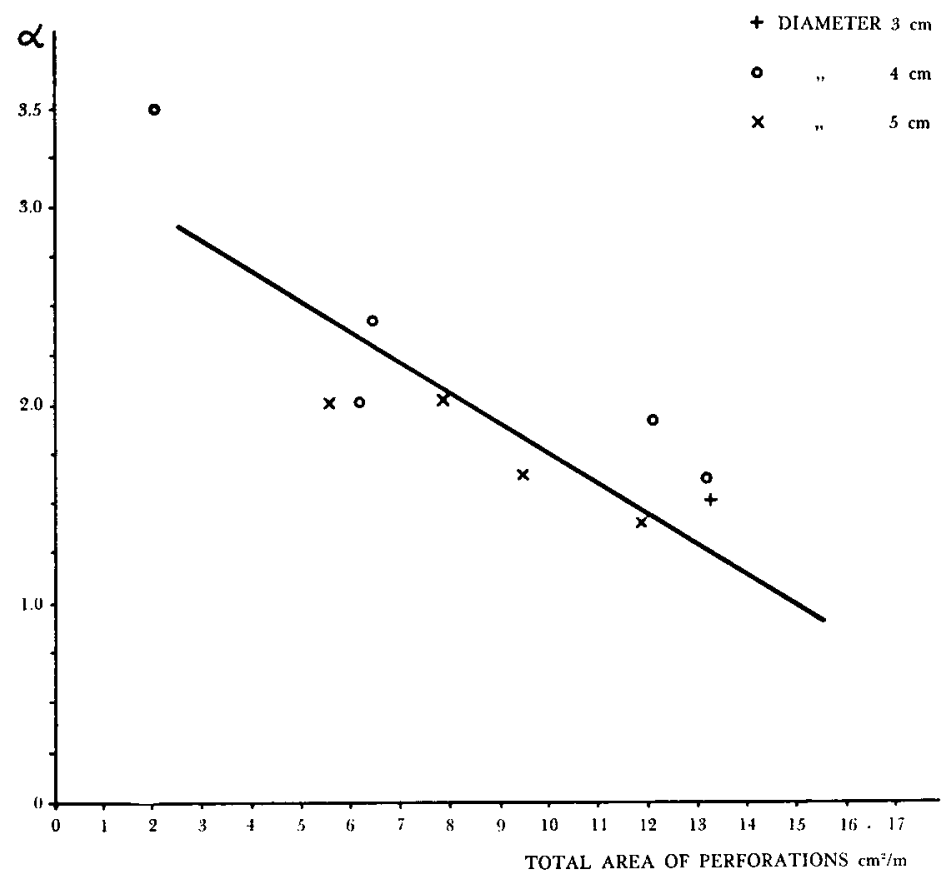

Fig. 5 Influence of perforation area on entry resistance, as defined by COEFFICIENT $a$.

With this coefficient the drainage performance of each pipe can also be defined.

Figure 5 shows the magnitude of $a$ (ordinate) dependent on the total area of perforations in $\mathrm{cm}^{2} / \mathrm{m}$ (abcis). The correlation coefficient is 0.77 .

Coefficient $\alpha$ for clay tiles is $0.9-1.0$, which agrees with a perforation area of $15 \mathrm{~cm}^{2}$ per $\mathrm{m}$. Unfortunately this area could not be measured exactly, but it is hardly to believe that there was $2 \mathrm{~mm}$ joint distance between the tiles.

It may be explained by supposing a change from laminar to turbulent flow in the vicinity of the drain when the draindiameter decreases.

\section{c Field experiments}

When the tank experiment was over, $5 \mathrm{~cm}$ plastic pipes were laid in different soils and compared with tile drains under the same conditions. These soils consisted of peat, clay, silty loam and sand. In measuring waterlevels and drain discharge during one winter, there could not be pointed out any reliable difference in drainage performance between plastic and tile drainage. Except in one case where the drains were laid in quicksand. Here the performance of the plastic drains was less good than of the tile drains, probably due to a large discharge of water under artesian pressure and a larger entry resistance of the plastic pipe. That this does not happen at the other field experiments can be attributed to the relative better hydraulic conductivity of the soil in the drain ditch. 


\section{REFERENCES}

1 Janert, H. : Der Greifwalder Rohrpflug und seine Arbeitsweise. Wasserwirtschaft Wassertechnik 5 (1955) 123.

2 Busch, C. D. : Low cost subsurface drainage. Agricultural Engineering 38 (1958) 92.

3 Wesseling, J.: Wanddikte, diameter en aantal perforaties van plastic drainbuizen. Not published.

4 Juusela, T. : Mole drainage with plastic strip lining. Fourth Congress International Commission on Irrigation and Drainage (1960) C. 387.

5 Hooghoudt, S. B. : Bijdragen tot de kennis van enige natuurkundige grootheden van de grond. Verslagen Landbouwkundige Onderzoekingen 46 (1940) no. 7.

6 EnNst, L. F.: Het berekenen van stationaire grondwaterstromingen welke in een verticaal vlak afgebeeld kunnen worden. Rapport Landbouwproefstation en Bodemkundig Instituut te Groningen (1954).

7 - - : Calculation of the steady flow of groundwater in vertical cross sections. Netherlands Journal of Agricultural Science 4 (1956) 126. 